\title{
Uso da metoclopramida na produção de leite em vacas em lactação
}

Jessica Quirino da Silva,Andressa Rodrigues Pereira, Henrique Getúlio da Silva, Gabriel Lorenzo Rezende Soares, Marcelo Alves da Silva"

Universidade Estadual do Norte do Paraná (UENP), Bandeirantes, PR, Brasil

*Autor correspondente

e-mail: masilva@uenp.edu.br

\section{Resumo}

Muitos são os estudos que buscam aumentar a produção de leite em vacas. A prolactina é um polipeptídio hormonal que estimula a produção e secreção de leite. Sua secreção ocorre em pulsos (12 pulsos em média em 24 horas), sendo estes prevalentes na madrugada (Touitou et al., 1992). A dopamina inibe a secreção de prolactina. Assim, a utilização de metoclopramida como um antagonista dopaminérgico pode aumentar os níveis de prolactina após sua administração, aumentando a produção de leite. Estudo realizado por Silva et al. (2013) demonstrou que a metoclopramida aumentou a produção de leite em novilhas com lactação induzida artificialmente. Desta forma, este estudo avaliou o feito da metoclopramida na produção leiteira em vacas em lactação. 0 trabalho foi conduzido na Fazenda Escola da Universidade Estadual do Norte do Paraná (UENP), localizada no município de Bandeirantes/PR. Foram utilizadas 14 vacas, com mais de 2 lactações, ordenhadas duas vezes por dia (6:00 e 15:00 h). 0 grupo controle (GI = 7) apresentou DEL médio de 225 dias e produção de 13,66 litros, e o grupo tratado com metoclopramida (GII = 7) apresentou DEL médio de 236 dias e produção de 111,07 litros. 0 grupo GI recebeu solução fisiológica intramuscular e o grupo GII recebeu três doses de 0,3 mg.kg-1 de metoclopramida (Plavet ${ }^{\circledR}$ ) por via intramuscular, administradas em 3 momentos com intervalos de 8 horas. Os animais foram acompanhados por 22 dias após a administração. Durante a execução do trabalho ocorreu a chegada de uma frente fria em Bandeirantes, que manteve a temperatura abaixo de $3{ }^{\circ} \mathrm{C}$ entre os dias D-1 e D6 do experimento, provocando geadas e alterando e prejudicando o manejo alimentar dos animais envolvidos no estudo. Isso gerou um aumento no coeficiente de variação na produção de leite e, por isso, optou-se por retirar os animais que apresentaram a maior e menor produção no período, ficando apenas 10 animais (cinco por grupo), além de converter a produção em porcentagens referentes ao dia anterior à aplicação da metoclopramida (D-1 = 100\%). Ao longo dos 22 dias acompanhados, a produção média dos animais tratados permaneceu acima da produção média dos 
animais não tratados (6,75\%), porém, sem apresentar diferença estatística exceto para o primeiro dia após a aplicação da metoclopramida, onde o grupo tratado produziu em média 18,09\% a mais de leite em relação ao grupo controle $(\mathrm{P}<0,05)$. Nas condições deste trabalho, a aplicação de metoclopramida aumentou a produção apenas no primeiro dia; contudo, mais estudos devem ser realizados em vacas com DEL menor, além de esclarecer-se os mecanismos e efeitos da metoclopramida na lactação de vacas. 